Tohoku J. exp. Med., 1971, 104, 331-334

\title{
Hypokalemia in Experimental Renovascular Hypertension
}

\author{
Jun Fujir and Yoshio Yazaki \\ Institute for Adult Diseases, Asahi Life Foundation, Tokyo
}

\begin{abstract}
FUJII, J. and YazakI, Y. Hypokalemia in Experimental Renovascular Hypertension. Tohoku J. exp. Med., 1971, 104 (4), 331-334 — Serial measurement of serum electrolytes was made in 15 rabbits from 1 to 9 weeks after the unilateral constriction of renal artery. Blood pressure promptly rose and remained raised. Serum potassium decreased from a control value of $4.08 \pm 0.09 \mathrm{mEq} / l($ mean $\pm \mathrm{sE}$ ) to $3.55 \pm 0.14 \mathrm{mEq} / l$ one week after the constriction of renal artery and remained reduced during the postoperative 9 weeks. Serum chloride showed only a temporary decrease and serum sodium showed no significant change during the period of observation. —_ hypokalemia; renovascular hypertension
\end{abstract}

Increasing attention has been paid to a particular association of hypokalemia and renovascular hypertension (Wrong 1961, Fitz and Armstrong 1964, Laidlaw et al. 1964, Barraclough et al. 1965, Campanacci and Magnani 1967, Krück 1968). Laidlaw et al. (1964) emphasized that patients with renovascular hypertension can mimic those with primary aldosteronism. Increased concentration of plasma renin and elevated secretion rate of aldosterone were observed by Barraclough et al. (1965) in hypertensive patients with renovascular lesions. Dustan et al. (1970) recently showed an inverse correlation between serum potassium and plasma renin activity in renovascular hypertension. We found in an experimental study (Fujii and Ikeda 1971) hypokalemia and increased plasma renin activity in some of rabbits with chronic renovascular hypertension. However, it remains unclear whether the hypokalemia develops in the early stage or only in the late stage of renovascular hypertension. In the present study a serial measurement of serum electrolytes was attempted from the acute to the chronic stages of experimental renovascular hypertension in the rabbit.

\section{Methods}

Fifteen male rabbits weighing $2-2.5 \mathrm{~kg}$. were used. They were fed pellets for the rabbit (Japan Clea Ltd, CR-1. Tokyo) which were relatively rich in sodium and potassium. Chemical analysis showed that the average content of sodium was $0.32 \mathrm{~g}$ and that of potassium was $1.02 \mathrm{~g}$ per $100 \mathrm{~g}$ of the pellets. Each animal was given $100 \mathrm{~g}$ of the pellets per day and tap water ad libitum. Blood pressure was measured at a weekly interval on the central ear artery by an indirect method (Kawaguchi 1931). Hypertension was produced by constricting unilateral renal artery (Fujii et al. 1969). Under pentobarbital anesthesia

Received for publication, January 16, 1971. 
(sodium pentobarbital $30 \mathrm{mg} / \mathrm{kg}$, intravenous) a silver elip of $0.9 \mathrm{~mm}$ in internal diameter was applied on the left renal artery. The right kidney was left untouched. Serum electrolytes were measured before and 1, 3, 5, 7, and 9 weeks after the constriction of renal artery. Blood was withdrawn from the ear vein without anesthesia. Sodium and potassium were analyzed by a flame photometry and chloride was analyzed by a titration method.

\section{RESULTS}

Results were summarized in Fig. 1. Blood pressure promptly rose from a control value of $85.2 \pm 2.1 \mathrm{~mm} \mathrm{Hg}$ (mean $\pm \mathrm{SE}$ ) to $127.7 \pm 3.6 \mathrm{~mm} \mathrm{Hg}$ at the postoperative one week and remained raised during the period of observation. erum potassium showed the most remarkable changes among serum electrolytes. It promptly decreased from a control value of $4.08 \pm 0.09 \mathrm{mEq} / l$ to $3.55 \pm 0.14$ $\mathrm{mEq} / l$ at the postoperative one week and remained reduced during the period of observation until the postoperative 9 weeks. Serum chloride also promptly decreased from a control value of $102.0 \pm 0.9 \mathrm{mEq} / l$ to $96.0 \pm 1.1 \mathrm{mEq} / l$ at the postoperative one week, but it returned to the previous level at the next week. Serum sodium did not show significant changes through the period of observation. There were no significant correlations between blood pressure and serum potassium level before and 1 week after the constriction of renal artery $(\mathbf{r}=+0.29$ and $\mathbf{r}=+$ 0.12 . respectively, $p>0.05$ in both cases). However, a significant inverse correlation was found between them at the postoperative 9 weeks $(r=-0.55, p<0.05)$.

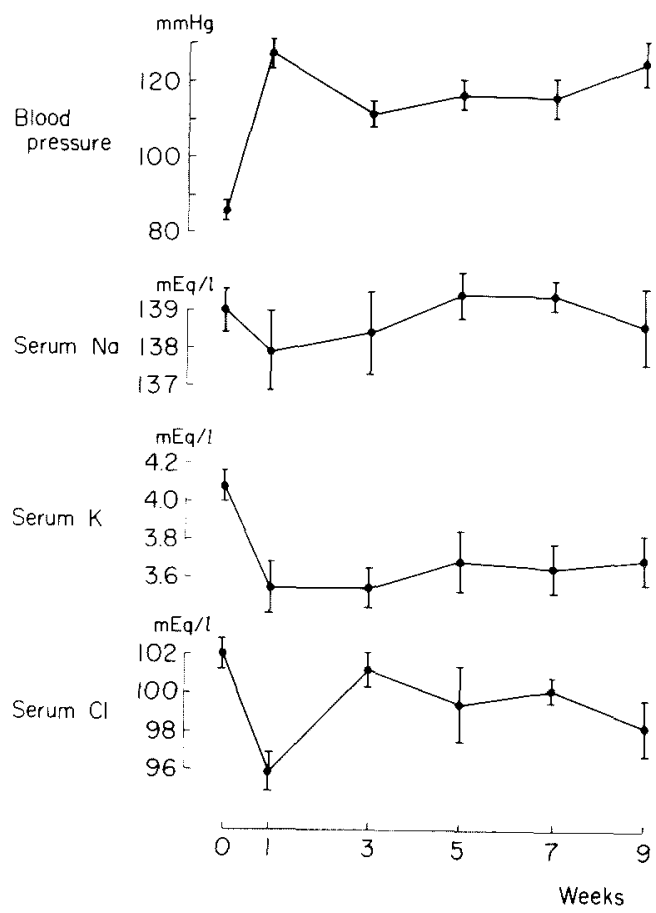

Fig. 1. Changes in blood pressure and serum electrolytes in 15 rabbits after unilateral constriction of renal artery. Values are means $\pm s s$. 


\section{Discussion}

The present study shows that hypokalemia develops as early as one week after the constriction of unilateral renal artery and persists for at least 9 weeks. The results partly agree with those of Blair-West et al. (1968) who produced hypertension in the sheep by constricting unilateral renal artery with untouched contralateral kidney. Plasma potassium significantly decreased in animals in which plasma sodium severely decreased. However, the observation of Blair-West et al. lasted only for postoperative 11 days. On the other hand, Ledingham (1953) reported that sodium and potassium in plasma were normal in rats with renovascular hypertension. He produced hypertension by constricting unilateral renal artery with contralateral nephrectomy. Plasma levels of sodium and potassium did not differ from those of normal animals after 9 to 88 hypertensive days. The difference in results might depend upon the presence or absence of the contralateral kidney. Regoli et al. (1962) noted that the renin content of the clipped kidney increased if the contralateral kidney was left untouched and did not increase if the contralateral kidney was absent. Aldosterone secretion is known to be stimulated by increased activity of the renin-angiotensin system. Although neither plasma renin activity nor aldosterone secretion rate was measured, increased release of renin from the clipped kidney might he responsible for the hypokalemia in the present study.

\section{References}

1) Barraclough, M.A., Bacchus, B., Brown, J.J., Davies, D.L., Lever, A.F. \& Robertson, J.I.S. Plasma-renin and aldosterone secretion in hypertensive patients with renal and renal artery lesions. Lancet, 1965, 2, 1310-1313.

2) Blair-West, J.R., Coghlan, J.P., Denton, E.A., Orchard, E., Scoggins, B.A. \& Wright, R.D. Renin-angiotensin-aldosterone system and sodium balance in experimental renal hypertension. Endocrinology, 1968, 83, 1199-1209.

3) Campanacci, D. \& Magnani, B. Hypertonie und Hypokaliämie. Münch. med. Wschr., 1967, 109, 1341-1350.

4) Dustan, H.P., 'Tarazi, R.C. \& Frohlich, E.D. Functional correlates of plasma renin activity in hypertensive patients. Circulation, 1970, 41, 555-567.

5) Fitz, A.E. \& Armstrong, M.L. Plasma vasoconstrictor activity in patients with renal, malignant, and primary hypertension. Circulation, 1964, 29, 409-414.

6) Fujii, J. \& Ikeda, M. Role of the renin angiotensin system in pathogenesis of experimental renal hypertension. Jap. Circulation J., 1971, 35, 493-498.

7) Fujii, J., Kurihara, H., Yamaguchi, H. \& Ikeda, M. Salt-rich diet and experimental renovascular hypertension in the rabbit. Toholu.J. exp. Med., 1969, 97, 191-196.

8) Kawaguchi, H. Über die konservative Blutdruckmessung am Kaninchen. J. Chiba med. Soc. (Jap.), 1931, 9, 293-306.

9) Krück, F. Hypokaliämische Hypertension. Internist, 1968, 9, 97-110.

10) Laidlaw, J.C., Yendt, E.R., Bird, C.E. \& Gornall, A.G. Hypertension due to renal artery occlusion simulating primary aldosteronism. Canad. med. Ass. J., 1964, 90, 321-325.

11) Ledingham, J.M. The distribution of water, sodium and potassium in heart and skeletal muscle in experimental renal hypertension. Clin. Sci., 1953, 12, 337-349. 
12) Regoli, D., Hess, R., Brunner, H., Peter, G. \& Gross, F. Interrelationship of renin content in kidneys and blood pressure in renal hypertensive rats. Arch. Internut. Pharmacodyn., 1962, 140, 416-426.

13) Wrong, O. Incdence of hypokalaemia in severe hypertension. Brit. med. J., 1961, 2, 419-421. 